\title{
SINCRONISMO ENTRE CLIENTES E FORNECEDORES
}

\section{RESUMO}

Este artigo trata da identificação da sincronia entre as expectativas das empresas clientes e as práticas de gerenciamento logístico de seus fornecedores, conforme o enfoque da gestão da cadeia de suprimentos. A pesquisa, de natureza exploratória, utilizou dados coletados por meio de questionários enviados aos executivos das empresas ligadas à Associação Brasileira da Indústria de Máquinas e Equipamentos (Abimaq). $O$ levantamento foi dividido em duas fases. Na primeira, trabalhou-se com uma amostra de 38 empresas clientes, ena segunda, com uma amostra de 51 empresas fornecedoras. Para tratamento dos dados, foram aplicadas técnicas estatísticas multivariadas, tendo o resultado evidenciado a existência do sincronismo para os fatores qualidade e confiabilidade entre as empresas clientes e seus fornecedores, dentro dos limites dessas amostras.

\section{Manuel Fernandes Silva Souza \\ Universidade Municipal de São Caetano do Sul}

\section{Roberto Giro Moori}

Universidade Presbiteriana Mackenzie

\section{Reynaldo Cavalheiro Marcondes}

Universidade Presbiteriana Mackenzie

\begin{abstract}
The article approaches synchrony identification between customers' expectations and managerial practices adopted by suppliers using the supply chain model. D ata were collected through questionnaires sent to executives of company members of the Abimaq (Brazilian Association of Machinery and Equipment Industry). The process was undertaken in two steps, one involving 38 executives from customer companies and another involving 51 executives from the supplying companies. Statistical treatment showed a strong evidence of synchronism for the variables quality and reliability between customer companies and their suppliers within the limits of the population sampled.
\end{abstract}

PALAVRAS-CHAVE Sincronização, desempenho competitivo, retenção de clientes, gestão da cadeia de suprimentos. KEYMORS Synchronism, competitive performance, key-factors, costumer retention, supply chain management. 


\section{INTRODUÇÃO}

No final da década de 1960, a Toyota desenvolveu 0 sistema just-in-time/kanban para reduzir o tempo decorrido entre o recebimento do pedido do cliente e a entrega do produto. Na década de 1970, o físico israelense Eliyahu Goldratt desenvolveu o software OPT (Optimized Production Technology) que resultou nos conceitos administrativos da TOC (Theory of Constraints). O OPT/TOC é um método de Planejamento e Controle da Produção que tenta otimizar a programação da produção pela maximização da utilização dos gargalos do processo produtivo. O OPT é considerado a gênese dos sistemas de gargalos (Davis et al., 2001, p. 549). 0 sincronismo, ou synchronous manufacturing, segundo Russell e Taylor III (1995, p. 694), surgiu na década de 1980, na General M otors e em outros fabricantes americanos, em substituição ao conceito TOC. N a década de 1990, a palavra "sincronismo" expandiu suas fronteiras, auxiliada pela introdução dos conceitos da gestão da cadeia de suprimentos (supply chain management) como uma extensão da logística. Sincronismo passou a ser sinônimo de conectividade dos elementos produtivos, centralizados nas expectativas do cliente, para, de forma síncrona - sem gargalos - , integrar a cadeia de suprimentos (Schonberger e Knod Jr., 1997).

N essa mesma época, com os ciclos de vida do produto se tornando cada vez mais curtos e os produtos tendendo a ficar rapidamente semel hantes aos de outras empresas, freqüentemente vistos como commodities, as empresas envolvidas nesse ambiente em competição passaram a fornecer serviços de valor agregado. $\mathrm{Na}$ verdade, tratou-se da inseparabilidade do produto e do serviço. A idéia de que o serviço ao cliente é um fator fundamental para a vantagem competitiva exigia dos fornecedores níveis de desempenho cada vez mais elevado. Como exemplo, Christopher (1999, p. 30) cita que em muitas organizações o enfoque voltado para a redução de estoques fez com que a qualidade do serviço de entrega dos fornecedores fosse reexaminada.

Por outro lado, os serviços exigidos pelos clientes não são estáticos. Há a necessidade de que os serviços prestados sejam colocados em sincronia com as expectativas e exigências dos clientes. As abordagens para a análise das questões empresariais mudam ao longo do tempo, exigindo que as relações contratuais entre os agentes sejam muito bem entendidas, uma vez que elas também sofrem mudanças. É de importância fundamental conhecer os fatores-chave que influenciam o comportamento dos clientes, identificando os fatores percebidos por ele como os mais relevantes, e, a partir daí, desenvolver processos de gerenciamentos logísticos para que os objetivos dos serviços ao cliente sejam atingidos. Assim, se o cliente enfatiza preço baixo, as estratégias corporativas devem ser elaboradas de tal forma que os processos de gestão da cadeia de suprimentos sejam capazes de coordenar e integrar as operações de aquisição, fabricação e distribuição a baixo custo (Christopher, 1997, p. 39; Fine, 1999, p. 77).

Este artigo parte da premissa de que os fatores de desempenho competitivo priorizados pelas empresas clientes são importantes fontes de tomada de decisão para as empresas fornecedoras implementarem ou melhorarem os seus processos de gerenciamento logístico. Dessa forma, este trabalho tem como ponto central verificar se as expectativas dos serviços aos clientes estão sincronizadas com as práticas gerenciais da cadeia de suprimentos de seus fornecedores. 0 objetivo é identificar decisões gerenciais contraditórias ou gargalos nos processos logísticos. A identificação pode ajudar a desencadear processos decisórios de natu rezas diversas, que poderão conduzir a ganhos no aprendizado e na disseminação de conhecimentos para os que atuam nesse campo de conhecimento.

\section{REFERENCIAL TEÓRICO}

\section{Serviç os ao cliente e a gestão da cadeia de suprimentos}

Até o início da década de 1970, a maioria das organizações manufatureiras focava a produção como uma função interna que tinha que ser apoiada no ambiente externo por outras funções da organização, como compras, finanças ou vendas. F ornecedores e clientes eram mantidos longe dos limites do piso da fábrica. Entretanto, com o acirramento da competitividade, as empresas estão reconhecendo que o processo produtivo não deve ficar isolado sob o pretexto de "manter 0 conhecimento em segredo" (Davis et al., 2001, p. 30). $\mathrm{Na}$ realidade, o processo de manufatura deve trabaIhar próximo aos clientes e fornecedores, e em igual intensidade, objetivando a otimização da cadeia de valor do produto (Porter, 1989).

Uma cadeia de valor pode ser definida como todas as atividades ou etapas que, de fato, agregam valor ao produto sem distinção de quanto e onde o valor é agregado. Esse conceito visa el iminar as atividades que não agregam valor, como as inspeções, estoques e movi- 
mentações de materiais (Handfield e Nichols J r., 1999). 0 resultado disso é um grau mais al to de dependência entre as funções de valor agregado que estão conectadas na cadeia. Essa integração entre fornecedores e clientes no processo de transformação tornou menos nítidos os limites entre as organizações, que antes eram vistos como independentes. Evidentemente, todas essas transformações visam apenas um único objetivo, que é a conquista do cliente (Gattorna e Walters, 1996; Christopher, 1997 e 1999).

Segundo Christopher (1999), o cliente de hoje, em quase todos os mercados, está exigindo níveis de desempenho de serviços mais elevados de seus fornecedores, sobretudo no que diz respeito à qualidade, entregas rápidas, flexibilidade e confiabilidade da entrega do produto. Em alguns casos, a personalização ou customização, como resultado direto dos avanços em tecnologias, permite que as empresas identifiquem e forneçam bens e serviços adaptados aos seus clientes (Davis et al., 2001, p. 85).

0 enfoque de Kotler (1999) para a vantagem competitiva considera que as empresas podem escolher entre cinco orientações para conduzir seus negócios: a orientação para a produção, a orientação para o produto, a orientação para as vendas, a orientação para 0 marketing e a orientação para o marketing societal. As três primeiras orientações são limitadas nos dias de hoje. A orientação para o marketing sustenta que a chave para alcançar metas organizacionais consi ste em determinar as necessidades e os desejos dos mercados-alvo e fornecer a satisfação desejada de forma mais eficiente do que a concorrência. A empresa deve iniciar com um mercado bem definido, concentrar-se na satisfação das necessidades dos clientes, e coordenar todas as atividades para esse objetivo, de maneira a produzir os lucros necessários. A orientação para 0 marketing societal (ou de causas sociais) exige que as empresas incluam considerações sociais, éticas e ecológicas em suas práticas de marketing, que também podem causar impactos na cadeia de suprimentos.

A essência da gestão da cadeia de suprimentos como uma extensão da logística está no planejamento e coordenação do fluxo de materiais da fonte até o consumidor final, como um sistema sincronizado e integrado. Essa nova prática se caracteriza pela cooperação e pela troca intensiva de informações. Por trás disso está o pressuposto de que com a visibilidade da demanda dos clientes e consumidores é possível alcançar, simultaneamente, substanciais reduções de estoques e meIhorias dos níveis de serviço (Arozo, 2003, p. 382).
N esse aspecto, os fatores de sucesso para uma cadeia de suprimentos são aqueles em que os membros têm excelência individual e compartilham valores, parcerias formalizadas, relacionamentos que preencham objetivos rel evantes para todos, e que seja concebida num contexto de flexibilidade e criação de valor conjunto, e não apenas de troca (Kanter, 1994). Cabe à gestão da cadeia de suprimentos a administração desses fatores, levando em conta que a maior parte deles deriva de uma al ocação pouco coordenada e fragmentada de atividades resultantes de uma deficiência na definição dos fatores-chave (Dornier et al., 2000, p. 371). Por isso, a identificação dos fatores-chave junto aos clientes, sincronizada com a capacidade do processo produtivo, é de fundamental importância para a conexão entre o mercado, aquilo que o cliente deseja, e 0 fornecedor de tal modo que os clientes recebam níveis de qualidade de serviços cada vez mais altos.

\section{Mensuração dos níveis de serviços}

A melhoria dos níveis de serviços repousa na idéia de que cada aspecto ou fator próprio pode ser melhorado. Contudo, cada um deles tem que ser medido e controlado de alguma maneira. A escolha das medidas desses fatores depende do conhecimento técnico que se tem das variações do objeto, da disponibilidade de recursos tecnológicos para a mensuração e da habilidade do gestor para o reconhecimento das medidas (Pereira, 1999, p. 53). De forma geral, para realizar medidas, al gumas variáveis ou fatores são concebidos para assumirem uma natureza quantitativa ou qualitativa. Slack et al. (2002) identificaram cinco medidas ou fatores de desempenho competitivo, a saber: (1) confiabilidade ou pontualidade, que significa produzir e entregar bens e/ou serviços em tempo hábil e nos prazos prometidos; (2) custo, que significa que quanto menos oneroso for produzir bens e serviços, menor poderá ser o preço para os consumidores. Para as empresas que concorrem diretamente em preço, o custo será o principal fator de controle. Mesmo entre as empresas que concorrem em outros aspectos que não o de preço, existe o interesse de manter seus custos baixos em relação à mão-de-obra, instalações e materiais; (3) flexibilidade, que significa a capacidade de atender a mudanças de produtos ou serviços, prazos de entrega ou volumes de produção, ampliando ou reduzindo a variedade de produtos ou serviços; (4) qualidade, que implica entregar bens ou serviços conforme as especificações ou necessidades do cliente; (5) vel ocidade ou agilidade de entrega, que significa o tem- 
po que o cliente deve esperar desde a emissão do pedido até o recebimento efetivo do produto.

Contudo, esses fatores de desempenho identificados por Slack et al. (2002) não são unânimes. Para Davis et al. (2001), os fatores principais de desempenho competitivo são: produtividade, capacidade, qualidade, velocidade de entrega, flexibilidade e velocidade do processo. Por sua vez, Pires $(2000$, p. 49) destaca como prioridades competitivas: o custo, como uma estratégia de manufatura baseada em conceitos de economia de escala; a curva de aprendizagem e produtividade; a qualidade, como a fabricação de produtos sem defeitos e conforme a especificação; os conceitos de confiabilidade e durabilidade; desempenho das entregas, relacionado à confiabilidade e à velocidade nos prazos de entrega dos produtos, conectados diretamente com a gestão da cadeia produtiva e de seus processos logísticos; e a flexibilidade, relacionada diretamente à existência de incertezas no ambiente produtivo, sendo, portanto, definida como a capacidade de mudança e adaptação às flutuações nas demandas de produção, especialmente na variedade e/ou tamanho dos lotes de produção. Para Tubino (1999), os principais fatores de desempenho podem ser colocados em quatro grupos: custo, qualidade, desempenho na entrega e flexibilidade.

Embora não haja concordância plena na definição dos fatores de desempenho, há o consenso de que para se melhorar o desempenho de qualquer fator-chave é indispensável que ele seja medido conforme a afirmação de Schröeder (1981) e Kaplan e N orton (1997): não se pode gerenciar o que não se pode medir. É raro que uma única medida seja usada para cada objetivo de desempenho, pois elas são compostas de muitas medidas menores. Usualmente utiliza-se um conjunto de medidas, cada uma com sua particular representação de objetivos de desempenho. Christopher (1997) sugeriu três dimensões para a medição do desempenho competitivo, a saber: a) o cliente deve ser a referência básica para a medição, uma vez que 0 mais importante são suas observações em relação ao desempenho; b) não é suficiente apenas comparar com o melhor da classe e; c) não são apenas os produtos que devem ser medidos e comparados, mas também os processos que os produzem. Essas três idéias estão na essência daquilo que se chama de benchmarking.

Assim, o benchmarking do serviço ao cliente pode ter como medidas: ciclo do pedido, atendimento completo do pedido, qualidade da documentação como a emissão da fatura sem erros, confiabilidade das entre- gas, apoio técnico e visitas de vendas. $\mathrm{N}$ a verdade, esses fatores fornecem uma visão parcial dos desempenhos, e muitos deles se sobrepõem em termos da informação que incluem. No entanto, é inegável a sua contribuição para a identificação, avaliação e rastreamento das áreas para melhoramento.

\section{PROCEDIMENTOS METODOLÓGICOS}

\section{Caracterização da cadeia de suprimentos}

Para a pesquisa foi escol hida a cadeia de suprimentos das empresas ligadas à Associação Brasileira de Máquinas e Equipamentos (Abimaq). Segundo dados de 2004, a Abimaq (2004) representava cerca de 4.500 empresas dos mais diferentes segmentos fabricantes de bens de capital mecânico. As empresas que compõem o setor de bens de capital podem ser divididas em dois segmentos. 0 primeiro, de bens de capital seriados, constituído de pequenos e médios produtores de capital nacional que atuam em segmentos como máquinas para calçados, rochas e granitos, têxtil e metalurgia, atendendo mercados de menor sofisticação. O segundo, de bens de capital por encomenda, constituído de um número menor de empresas de grande porte, boa parte delas multinacionais, que atuam na venda de soluções e serviços, como nos sistemas de responsabilidade total sobre o projeto (turn key) e de provedores de soluções (Comex, 2003).

0 setor de máquinas e equipamentos é tradicionalmente reconhecido como estratégico para um padrão de desenvolvimento sustentado, tendo em vista o papel que desempenha na acumulação de capital e difusão do progresso técnico. A importância da Abimaq (2004) para o Brasil pode ser verificada pelo faturamento de 2004, estimado em $\mathrm{R} \$ 40$ bilhões. No período entre janeiro e agosto de 2004, o setor faturou $R \$$ 28,6 milhões, empregou 202 mil trabalhadores e exportou US\$ 4,2 bilhões.

\section{Operacionalização das variáveis}

Para verificar se as expectativas dos clientes estavam sincronizadas com as práticas gerenciais da cadeia de suprimentos de seus fornecedores, as variáveis foram operacionalizadas da seguinte forma:

- independentes, representadas pelos fatores-chave de desempenho competitivo identificados pelas empresas clientes. Essa escolha se deu porque as assertivas ou variáveis que compõem os fatores-chave flutuam conforme as necessidades do mercado; 
- dependentes, representadas pelas práticas gerenciais da cadeia de suprimentos das empresas fornecedoras. Nesse caso, as variáveis que compõem as práticas gerenciais têm uma alta interação com 0 ambiente interno da empresa, não suportan do flutuações bruscas do mercado. No entanto, essas variáveis foram ajustadas às necessidades do ambiente externo;

- intervenientes, representadas pel os processos de decisão. É da qualidade das ações gerenciais emanadas do corpo administrativo das empresas que se obtém a tão desejada competitividade. As variáveis definidas como fatores-chave, práticas gerenciais e ações gerenciais estão representadas na Figura 1.

Pode se observar na Figura 1 que o foco do estudo está nas inter-relações entre as funções compras do cliente, a jusante, e vendas do fornecedor, a montante. No entanto, é prudente verificar que uma empresa situada a jusante da cadeia pode ser fornecedora de produtos a uma empresa situada a montante da cadeia e vice-versa. Para citar um exemplo: uma fábrica de parafusos pode vender parafusos para uma empresa do setor de bens de capital seriado situada a sua jusante, bem como adquirir um equipamento para a produção de parafusos de uma empresa posicionada a seu montante. A observação desse fato foi importante para a elaboração dos instrumentos da coleta dos dados.

\section{Coleta, amostra e tratamento dos dados}

A pesquisa foi de natureza exploratória, do tipo descritivo, cuja coleta de dados se deu em dois períodos distintos. A primeira coleta se deu no último trimestre de 2001, a jusante da cadeia de suprimentos. Para tanto, aplicou-se um questionário composto de questões fechadas, enviado aos executivos da área de suprimentos/compras das empresas selecionadas. A razão da escol ha dessa área, em detrimento de uma função técnica (engenheiro ou correlato), foi porque as assertivas eram basicamente de cunho logístico e administrativo. Assim, procurou-se levantar o perfil do respondente e da empresa, e os fatores-chave do ponto de vista dos clientes para a sua retenção. A definição dos fatores-chave foi feita com base nos conceitos dos principais fatores de desempenho competitivos emitidos pelos diversos autores mencionados na seção Referencial Teórico. É importante ressaltar que se buscou conhecer a intenção do cliente de voltar a comprar do mesmo fornecedor. Foram formuladas 10 assertivas escolhidas como as mais representativas dentre inúmeras outras. Essas assertivas foram colocadas em uma escala ordinal, tipo Likert, composta de seis categorias de respostas: discordo total mente (DT), discordo muito (DM), discordo pouco (DP), concordo pouco (CP), concordo muito (CM) e concordo totalmente (CT). A escol ha dessa escala foi motivada pela sua capacidade de verificar o grau de concordância com a assertiva apresentada, mostrando-se apropriada a medir sutilezas de atributos de uma mesma categoria de fenômenos (Saaty, 1991, p. 67). Além disso, el a tem uma relação adequada entre a precisão e a acurácia da mensuração. U ma escala de 11 pontos (de 0 a 10) aportaria um refinamento de precisão à medida, mas em contrapartida implicaria a perda da acurácia, já que dificilmente se disporia de onze rótulos distintos para a classificação qualitativa do fenômeno estudado ( $\mathrm{Pe}$ reira, 1999).

Figura 1 - Conexões das variáveis e a cadeia de suprimentos.
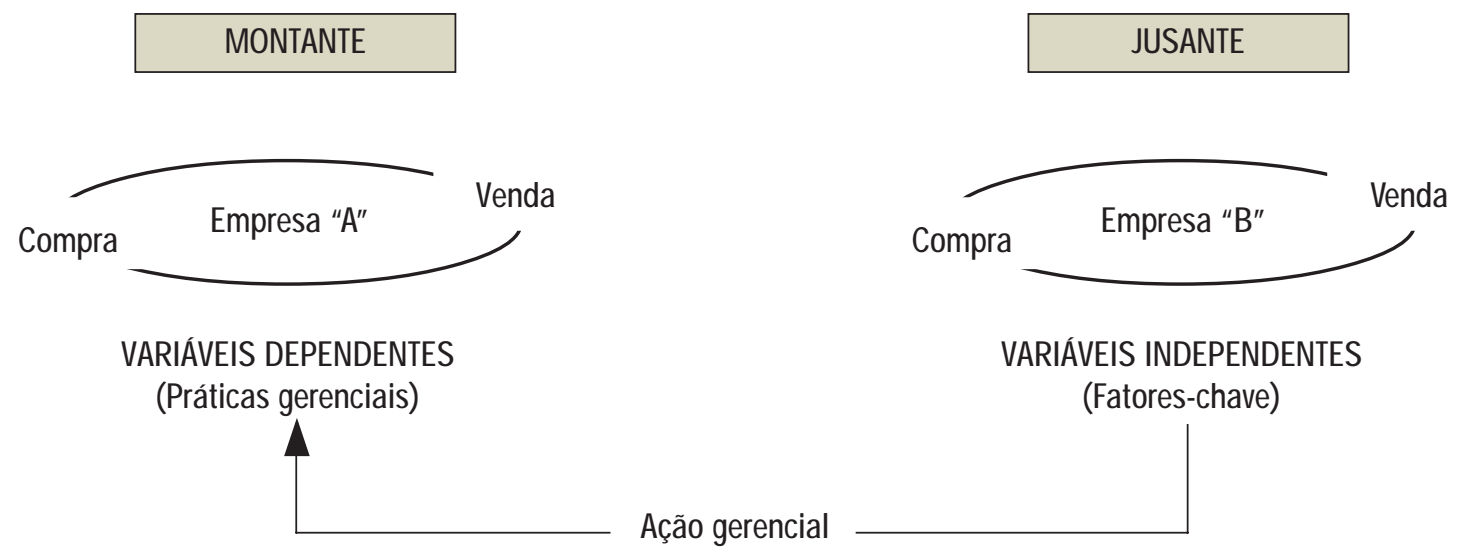

40 - oRAE - VOL. $45 \cdot \mathrm{N} 04$ 
Assim, testado e val idado o questionário construído, atividade esta facilitada pelo fato de um dos autores deste artigo ser funcionário de uma empresa associada à A bimaq, prosseguiu-se na escolha da amostra de empresas. Escolhida por conveniência, a amostra foi constituída de 90 empresas "clientes", situadas nos estados de São Paulo, Rio de Janeiro, Rio Grande do Sul, Paraná, Minas Gerais e Bahia. 0 tratamento dos dados se deu por meio da aplicação das seguintes técnicas: a) estatística descritiva, para tratar das descrições dos dados coletados por meio de porcentagens, freqüência dos dados e moda das respostas obtidas; b) estatística multivariada, a técnica da análise fatorial, com a finalidade de reduzir o número de variáveis e identificar os componentes principais para a retenção dos clientes; e c) coeficiente Alfa de Cronbach para verificar se os atributos que compuseram o fator-chave tinham uma consistência interna aceitável entre si numa escala somada. Em geral, os limites mínimos de aceitação para o Alfa de Cronbach ficam entre 0,6 e 0,7 (Hair et al., 1998).

A segunda coleta ocorreu no segundo trimestre de 2002, a montante da cadeia de suprimentos, logo após os resultados da primeira coleta dos dados. A primeira coleta de dados apresentou como resultado a priorização pelas empresas clientes de três fatores-chave de desempenho competitivo, a saber: qualidade, confiabilidade e preço, respectivamente. Assim, elaborou-se um novo questionário para verificar o grau de importância que a gestão da cadeia de suprimentos nas empresas fornecedoras dava a esses fatores-chave.
Esse questionário, composto de questões fechadas, foi enviado aos executivos das áreas produtivas, como planejamento e controle da produção, produção e controle de qualidade das empresas selecionadas. A razão para a escolha de executivos dessas áreas foi porque 0 seu nível hierárquico possibilitaria um melhor julgamento da assertiva apresentada.

Da mesma forma que na primeira fase, com a coleta dos dados procurou-se levantar o perfil dos respondentes e da empresa, e o grau de discordância/concordância em relação aos fatores-chave identificados pelas empresas fornecedoras. Para tanto, foram formuladas 18 assertivas, sendo que os três fatores-chave qualidade, confiabilidade e preço - foram enunciados de forma semel hante ao questionário da primeira fase para medir o mesmo fenômeno - agora sob o ponto de vista do fornecedor - , visando mensurar o sincronismo entre as expectativas das empresas clientes e as práticas gerenciais das empresas fornecedoras. Além disso, foram elaboradas mais cinco assertivas de cada fator-chave como subsídios para reforçar ou refutar 0 sincronismo. 0 Quadro 1 mostra, para o fator-chave preço, a assertiva elaborada para as empresas clientes, identificada com a letra $C$, a sua repetição junto às empresas fornecedoras, identificada pela letra $F$, e as cinco assertivas de mesma categoria, identificadas pelos números de 1 a 5.

Esse mesmo procedimento foi adotado para os outros dois fatores-chave, qualidade e confiabilidade. Assim, discutido, testado e validado o questionário construído, prosseguiu-se na escolha da nova amostra

Quadro 1 - 0 fator-chave preço e as assertivas da mesma categoria.

\begin{tabular}{|l|l|l|}
\hline C & O preço é importante para que a minha empresa continue comprando do mesmo fornecedor & Preço \\
\hline F & $\begin{array}{l}\text { Ter o preço de vendas dos produtos menor que o dos concorrentes é muito importante para } \\
\text { que minha empresa continue vendendo para os mesmos clientes }\end{array}$ & $\begin{array}{l}\text { Desejo de preço menor que } \\
\text { o dos concorrentes }\end{array}$ \\
\hline 1 & $\begin{array}{l}\text { Os preços de venda dos produtos da minha empresa são mais baixos que os dos concor- } \\
\text { rentes }\end{array}$ & $\begin{array}{l}\text { O preço é menor do que o } \\
\text { dos concorrentes }\end{array}$ \\
\hline 2 & A minha empresa conhece todos os seus custos operacionais, inclusive dos estoques & $\begin{array}{l}\text { Conhece os custos opera- } \\
\text { cionais }\end{array}$ \\
\hline 3 & Os custos operacionais da minha empresa são constantemente avaliados & $\begin{array}{l}\text { Os custos operacionais são } \\
\text { avaliados }\end{array}$ \\
\hline 4 & $\begin{array}{l}\text { A minha empresa conhece o impacto dos seus custos operacionais sobre os preços de } \\
\text { venda de seus produtos }\end{array}$ & $\begin{array}{l}\text { Conhece o impacto dos cus- } \\
\text { tos no preço }\end{array}$ \\
\hline 5 & $\begin{array}{l}\text { Os custos operacionais da minha empresa permitem a prática de preços de venda compa- } \\
\text { tíveis com o mercado }\end{array}$ & $\begin{array}{l}\text { Os custos praticados são } \\
\text { competitivos }\end{array}$ \\
\hline
\end{tabular}


de empresas. Selecionada por conveniência, a amostra foi composta de 210 empresas fornecedoras. 0 número de empresas fornecedoras foi maior do que o número de empresas clientes para se garantir uma maior robustez das análises.

Para o tratamento dos dados, foram utilizados: a) a estatística descritiva, para tratar das descrições dos dados coletados por meio de freqüências, porcentagens e moda das respostas obtidas; b) o teste não paramétrico do Qui-Quadrado $\left(\chi^{2}\right)$, para verificar se havia uma associação ou dependência entre as variáveis das empresas clientes e empresas fornecedoras; c) o teste não paramétrico de Mann-Whitney, para verificar se as amostras referentes às empresas clientes e empresas fornecedoras eram significativamente diferentes; e d) o coeficiente Alfa de Cronbach, para verificar a consistência interna das cinco assertivas em relação ao fator-chave.

\section{ANÁLISE DOS DADOS E RESULTADOS}

\section{Perfil das empresas clientes}

No último trimestre de 2001 foram enviados 90 questionários às empresas clientes, direcionados aos executivos de compras/suprimentos. Desses questionários, 38 retornaram. U ma amostra com mais de 30 respondentes pode ser classificada como de "tamanho grande", sendo passível de se aplicarem as técnicas estatísticas inferenciais (Costa N eto, 1977, p. 73). No entanto, quando se aplicam testes inerentes à técnica da análise fatorial, o tamanho da amostra utilizada neste estudo estaria aquém do mínimo desejável, conforme sugerem Malhotra (1999) e Hair et al. (1998).

Não obstante essa possível deficiência, a amostra revelou algumas características importantes, que de al guma forma procuram atenuar problemas relacionados ao seu tamanho, mesmo porque a pesquisa é de natureza exploratória e não probabilística. A amostra foi constituída basicamente de diretores e gerentes de compras de grandes empresas dos setores metalúrgico, químico, petroquímico e de máquinas e equipamentos, com o seguinte perfil: a) 57,9\% dos respondentes ocupavam o cargo de diretor ou gerente de compras e $42,1 \%$ o cargo de supervisor de compras ou correlato; b) $15,8 \%$ das empresas pertenciam ao setor metalúrgico, 2,6\% ao siderúrgico, $13,2 \%$ ao químico, $15,8 \%$ ao petroquímico, $13,2 \%$ ao de máquinas e equipamentos, e $39,5 \%$ a outros setores, como serviços e beneficiadores de metais não ferrosos; e c) 2,6\% das empresas tinham um faturamento anual de até $R \$ 12$ milhões, $15,8 \%$ de $R \$ 12$ milhões a $R \$ 120$ milhões e $81 \%$ acima de $\mathrm{R} \$ 120$ milhões.

\section{Grau de importância dos fatores-chave}

Os dados coletados por meio das 10 assertivas distribuídas pela escala de discordância/concordância foram tratados mediante a aplicação da freqüência de ocorrência, de modo a determinar os fatores-chave mais importantes para a retenção do cliente. $\mathrm{N}$ a Tabela 1 estão apresentadas as freqüências das respostas obtidas.

Tabela 1 - \% de respostas atribuídas aos atributos para a retenção do cliente.

\begin{tabular}{|c|c|c|c|c|c|c|c|c|}
\hline \multirow{2}{*}{\multicolumn{2}{|c|}{ FATORES-CHAVE }} & \multicolumn{6}{|c|}{ ESCALA } & \multirow[t]{2}{*}{ MODA } \\
\hline & & (DT) & (DM) & (DP) & $(\mathrm{CP})$ & $(\mathrm{CM})$ & (CT) & \\
\hline 1 & Preço & 5,3 & 0 & 0 & 15,8 & 34,2 & 44,7 & CT \\
\hline 2 & Assistência técnica & 0 & 0 & 0 & 7,9 & 42,1 & 50,0 & CT \\
\hline 3 & Sistema de garantia da qualidade & 0 & 0 & 2,6 & 26,3 & 31,6 & 39,5 & CT \\
\hline 4 & Garantia dos produtos & 0 & 0 & 0 & 5,3 & 28,9 & 65,8 & CT \\
\hline 5 & Qualidade dos produtos & 0 & 0 & 2,6 & 2,6 & 13,2 & 81,6 & CT \\
\hline 6 & Informação posição dos pedidos & 0 & 0 & 0 & 7,9 & 52,6 & 39,5 & CM \\
\hline 7 & Velocidade de entrega & 0 & 0 & 0 & 13,2 & 36,8 & 50,0 & CM \\
\hline 8 & Confiabilidade de entrega & 0 & 2,6 & 0 & 0 & 28,9 & 68,4 & CT \\
\hline 9 & Flexibilidade & 0 & 0 & 2,6 & 10,5 & 47,4 & 39,5 & CM \\
\hline 10 & Rastreabilidade dos Produtos & 0 & 0 & 0 & 18,4 & 31,6 & 50,0 & $\mathrm{CM}$ \\
\hline \multicolumn{2}{|c|}{$\begin{array}{l}\text { (DT) Discordo Totalmente } \\
\text { (DM) Discordo Muito } \\
\text { (DP) Discordo Pouco }\end{array}$} & \multicolumn{6}{|c|}{$\begin{array}{l}\text { (CP) Concordo Pouco } \\
\text { (CM) Concordo Muito } \\
\text { (CT) Concordo Totalmente }\end{array}$} & \\
\hline
\end{tabular}


Os resultados obtidos com o tratamento dos dados indicaram uma acentuada incidência de respostas no ponto de concordância da escala para o fator "qualidade dos produtos", sendo a maior freqüência ( $81,6 \%$ ) verificada no grau de importância da escala "concordo total mente". Seguem, por grau de importância, em segundo e tercei ro lugares, as assertivas referentes aos fatores "confiabilidade de entrega" e "garantia dos produtos", respectivamente. Em quarto lugar aparecem com a mesma freqüência de $50,0 \%$ as assertivas referentes aos fatores "assistência técnica", "vel ocidade de entrega" e "rastreabilidade dos produtos". O bserva-se que apenas o fator "qualidade dos produtos" apareceu em evidência. Os demais fatores apareceram em suas colocações com freqüências de ocorrência muito próximas e com um grande número de variáveis ou fatores-chave.

Havia a possibilidade de inferir o mesmo resultado a partir da investigação de um conjunto menor de fatores-chave, mediante sua identificação naquele conjunto de variáveis. Isso seria viável com a aplicação da técnica da análise fatorial, que, segundo Hair et al. (1998), é recomendada nos seguintes casos: a) identificar a estrutura de um conjunto de medições; b) reduzir uma grande massa de dados da pesquisa em uma quantidade gerenciável; c) auxiliar o pesquisador na construção de escalas, reagrupando as variáveis em fatores independentes e atribuindo um peso a cada variável para ser combinado na escala; e, d) identificar fatores não correlacionados. Evidentemente, em algumas ocasiões é possível intuir que várias medidas podem compor um fator (ou indicador). No entanto, é preferível, em vez de propor subjetivamente a criação de um indicador, submeter os dados da amostra a uma análise fatorial que aponte objetivamente para essa agregação de medidas (Pereira, 1999).

\section{Análise fatorial para os fatores-chave}

$\mathrm{Na}$ aplicação da técnica da análise fatorial, foi necessário inicial mente efetuar diversos testes estatísticos para verificar a ad equação dos dados coletados às premissas básicas. Os resultados obtidos foram: a) determinante da matriz de correlações igual a 0,099 (diferente de zero); b) KMO (Kaiser-Meyer-Olkin)/ Measure of Sampling Adequacy (MSA) igual a 0,62 (superior a 0,6); c) BTS (Bartlett's Test of Sphericity) igual a 77,410 e nível de significância igual a 0,00 (menor que $5 \%$ ); e, d) a revelação dos fatores "garantia dos produtos" e "informações da posição dos pedidos" como elementos isolados ou independen- tes, dada a baixa interatividade com os outros elementos. Para se constatar que os fatores "garantia dos produtos" e "informações da posição dos pedidos" tinham uma baixa interatividade com os outros elementos, foi necessário gerar matrizes de correlação e de antiimagem, porque o resultado do KMO inicialmente obtido foi considerado inaceitável por ter ficado abaixo de 0,6.

Satisfeitas as premissas básicas, prosseguiu o tratamento dos dados. 0 passo seguinte foi a extração dos fatores principais, suprimindo os fatores "garantia dos produtos" e "informações da posição dos pedidos". A aplicação da técnica da análise fatorial pelo critério varimax with kaizer normalization (Hair et al., 1998) possibilitou a identificação de três componentes principais para os fatores de retenção do cliente correspondentes aos autoval ores (eigenvalues) maiores do que 1 , iguais a 2,661, 1,695 e 1,262, e representativos de $70,231 \%$ da variância do conjunto de dados originais.

No Quadro 2 estão apresentados os resultados da análise fatorial aplicada a esses fatores-chave de retenção do cliente, onde se destacam os componentes principais, caracterizadores dos fatores extraídos.

O primeiro fator, denominado "fator principal", englobou três variáveis originais, as de números 1 , 5, e 8. A análise desses dados evidenciou que eles estão diretamente relacionados aos "aspectos principais" quando um cliente realiza a compra.

Assim, assumiu-se que esse fator esteja relacionado com o aspecto emocional ou da consciência intuitiva do cliente para a viabilização de seus negócios. O segundo fator, denominado "fator secundário", foi explicado por três variáveis, as de números 7, 9 e 10. 0 terceiro fator, denominado "fator interno", foi evidenciado por duas variáveis originais, as de números 2 e 3, integrantes do sistema de gestão da qualidade. Os fatores "garantia dos produtos" e "informações da posição dos pedidos" revelaram-se elementos isolados ou independentes. Isso se deveu à sua baixa interatividade com os outros el ementos. Como conseqüência, os 10 fatores de retenção foram reduzidos a apenas cinco, a saber: fator principal, fator secundário, fator interno, "garantia dos produtos" e "informações da posição dos pedidos".

Observa-se ainda no Quadro 2 que o fator principal, o fator secundário e o fator interno têm uma consistência ou confiabilidade interna, dada pelo alfa de Chronbach, de 0,8008, 0,6758 e 0,5393, respectivamente. Assim, os 10 fatores-chave de desempenho 
competitivo ou retenção do cliente podem ser resumidos a cinco fatores: principal, secundário, interno, garantia dos produtos e informações da posição dos pedidos. 0 "fator principal" e o "fator secundário", sozinhos, explicam quase $55 \%$ da variância, e seus componentes têm coerência ou similaridades quanto ao seu agrupamento. Os demais fatores representam o restante das variâncias explicadas.

Por outro lado, o intervalo de val ores possíveis para - Alfa de Cronbach está entre 0 e 1, e o julgamento da combinação dos fatores-chave resultantes dos valores obtidos, se satisfatória ou não, cabe exclusivamente ao pesquisador, pois não há um ponto de corte ideal que se possa arbitrar para a concepção de qualquer indicador (Pereira, 1999). Com isso, os 10 fatores-chave de retenção puderam ser resumidos a apenas dois: fator principal e fator secundário, pois, além de representarem quase $55 \%$ da variância, continham em sua composição os principais fatores-chave de retenção ao cliente.

Para atingir o objetivo principal de verificar se os fatores-chave identificados pel os clientes estavam sincronizados com a gestão da cadeia de suprimentos dos fornecedores, considerou-se apenas o fator principal porque nele estavam contidos os principais fatoreschave da competitividade: 0 preço, a qualidade e a confiabilidade.

Assim, definidos os fatores-chave priorizados pelas empresas clientes, partiu-se para a segunda fase da pesquisa, na qual foi realizada uma segunda coleta de dados para verificar se havia a prática do gerenciamento, nas empresas fornecedoras, desses três fatores-chave priorizados pelos clientes.

\section{Perfil das empresas fornecedoras}

No segundo trimestre de 2002 foram enviados 210 questionários aos executivos das áreas produtivas das empresas fornecedoras. Desse total, 51 retornaram. Quanto ao tamanho da amostra, as mesmas observações feitas anteriormente para a amostra das empresas clientes permanecem válidas. A amostra foi constituída basicamente de diretores e gerentes de vendas, qualidade, logística e de produto, grandes empresas dos setores metalúrgicos e de máquinas e equipamentos, com o seguinte perfil: a) $51,0 \%$ dos respondentes ocupavam o cargo de diretor ou gerente comercial/vendas ou marketing, 7,8\% ocupavam 0 cargo de supervisor comercial/vendas ou marketing, e $41,2 \%$ ocupavam outros cargos, tais como diretor administrativo, diretor executivo, gerente da qualidade, gerente de logística, gerente de produtos, coordenador comercial e assistente comercial; b) 37,3\% das empresas pertenciam ao setor metalúrgico, 45,1\% ao de máquinas e equipamentos, e $17,6 \%$ a outros setores, tais como telecomunicações, el etroel etrônicos e automação industrial; c) 2,0\% das empresas tinham um faturamento anual de até R $\$ 12$ milhões, $11,8 \%$ de $R \$ 12$ milhões a $R \$ 120$ milhões, e $86,3 \%$ acima de $R \$ 120$ milhões.

\section{Grau de importância dos fatores-chave}

Os dados ordinais levantados por meio das assertivas da segunda fase da pesquisa foram tratados mediante distribuição de freqüências de ocorrência. $\mathrm{Na}$ Tabela 2 estão apresentados os resultados para os atributos dos fatores-chave de retenção do cliente.

Quadro 2 - Fatores determinantes relacionados aos fatores-chave.

\begin{tabular}{|c|c|c|c|}
\hline ORDEM DO FATOR & DENOMINAÇÃO & $\begin{array}{l}\text { VARIÁVEIS DETERMINANTES } \\
\text { (FATORES-CHAVE) }\end{array}$ & $\begin{array}{l}\text { ALFA DE } \\
\text { CRONBACH }\end{array}$ \\
\hline 1 & Fator principal & $\begin{array}{l}\text { Preço } \\
\text { Qualidade dos produtos } \\
\text { Confiabilidade de entrega }\end{array}$ & 0,8008 \\
\hline 2 & Fator secundário & $\begin{array}{l}\text { Velocidade de entrega } \\
\text { Flexibilidade } \\
\text { Rastreabilidade dos produtos }\end{array}$ & 0,6758 \\
\hline 3 & Fator interno & $\begin{array}{l}\text { Assistência técnica } \\
\text { Sistema de garantia da qualidade }\end{array}$ & 0,5393 \\
\hline 4 & & Garantia dos produtos & \\
\hline 5 & & Informações da posição dos pedidos & \\
\hline
\end{tabular}


Observa-se que 0 atributo mais significativo foi a "qualidade dos produtos vendidos", com $88,2 \%$ das respostas assinaladas em "concordo total mente" (CT) na escala de valor, mostrando que esse seria um atributo importante para a empresa fornecedora ou fabricante. Essa primeira colocação condiz com o fatorchave evidenciado pelo cliente para a sua retenção, embora não com a mesma amplitude, o que poderia sugerir que a empresa fabricante enfatiza as suas competências na busca da qualidade. Os demais atributos desse fator-chave também apareceram com destaque, embora dispersos, para outros valores de concordân- cia, mesmo em amplitude menor, para valores de discordância, cuja consistência interna dada pelo Alfa de Cronbach foi de 0,6582 , ficando dentro dos limites mínimos aceitáveis.

Para o fator-chave "confiabilidade" 0 atributo "confiabilidade da entrega de vendas", com $68,6 \%$ das respostas assinaladas em "concordo totalmente" (CT) na escala de valor, mostra que esse seria o segundo fator mais importante para a empresa fabricante. Os demais atributos apareceram distribuídos em outras escalas de valores, evidenciando que não existe uma unanimidade quanto à importância desse fator-chave para a

Tabela 2 - Atributos dos fatores-chave.

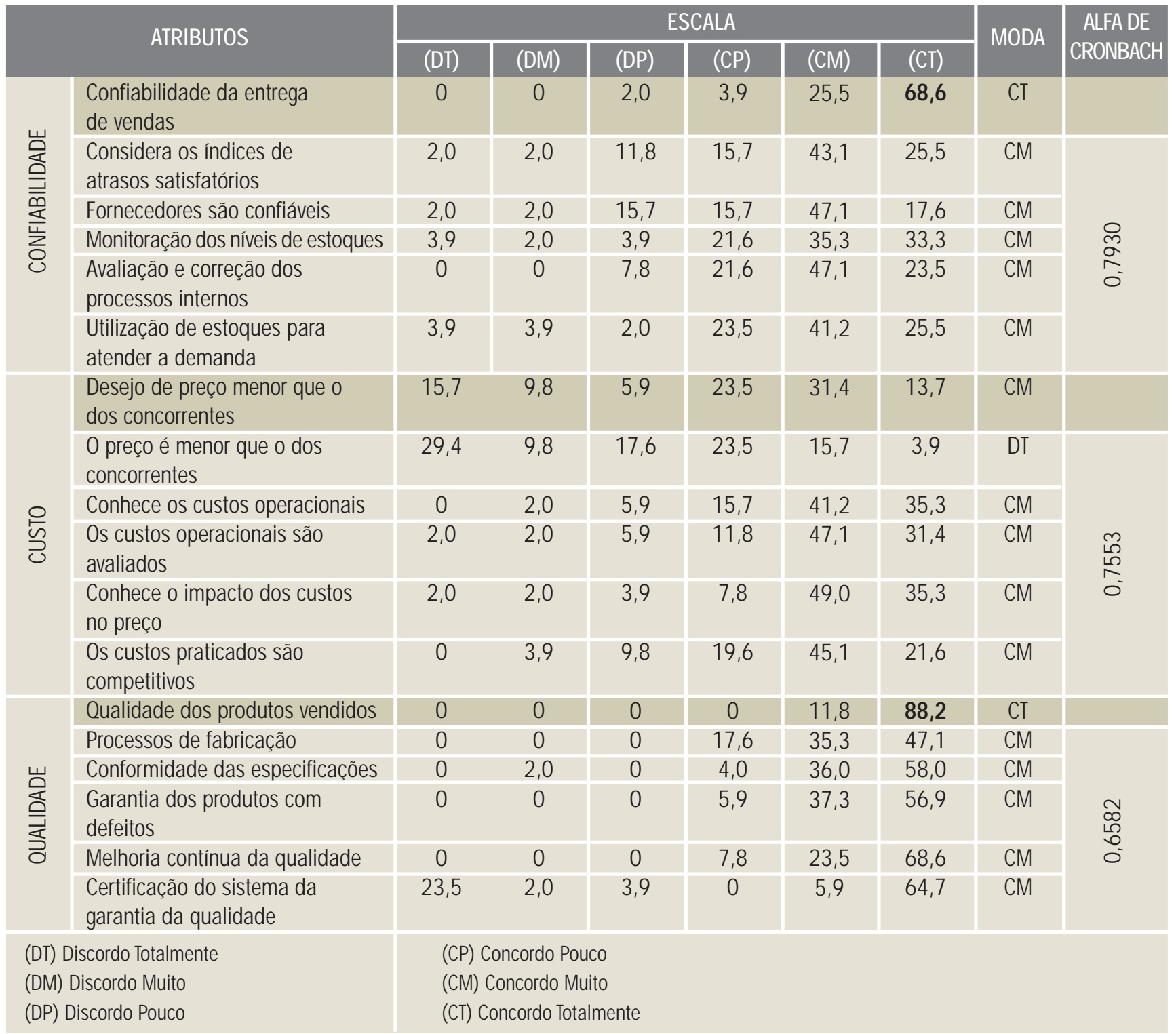


sua competitividade. A consistência interna dada pelo Alfa de Cronbach foi de 0,7930.

Com uma consistência interna de 0,7553 pelo Alfa de Cronbach, o fator-chave denominado "custos" foi o que apresentou o pior resultado em termos de gestão nas empresas fabricantes, mostran do que a vantagem competitiva não está em custos, mas sim em qualidade. Na pesquisa da primeira fase, os clientes evidenciaram que o preço é um fator importante, com $44,7 \%$ das respostas obtidas. Essa freqüência de respostas priorizou o fator preço em sétimo lugar na escala de valor, "concordo totalmente" (CT), conforme foi mostrado na Quadro 1.

\section{Sincronismo entre empresas: clientes e fornecedoras}

Conhecidas as prioridades dos fatores-chave de desempenho que influenciam o comportamento das empresas compradoras (ou clientes) e as práticas de gestão da cadeia de suprimentos nas empresas fornecedoras, será analisada, a seguir, a existência de sincronismo entre as duas partes. Com base nos três fatores-chave priorizados pelos clientes - qualidade, confiabilidade e preço - e suas práticas pelos fornecedores, é apresentado na Tabela 3 um resumo das freqüências de respostas em suas respectivas escalas.
U ma anál ise visual dos dados da Tabela 3 revela que: a) os três fatores - confiabilidade, preço e qualidade aparecem com maior freqüência de respostas no lado "concordo" da escala; b) o fator preço apresenta um desequilíbrio de respostas no lado "discordo" da escala; e c) o fator qualidade teve freqüência de resposta igual a zero nas escalas "discordo totalmente" e "discordo muito". Assim, esse resultado parece evidenciar que os fatores confiabilidade e qualidade estão sincronizados. 0 mesmo não se pode dizer com relação ao fator preço.

A partir dessa evidência inicial, buscou-se confirmar esse fato estatisticamente. A plicando-se técnicas de estatística inferencial, procurou-se verificar, a saber: a) se havia uma associação ou dependência entre os fatores-chave das empresas clientes e das empresas fornecedoras; b) se havia correlação entre os fatoreschave das empresas clientes e das empresas fornecedoras; e c) se as amostras dos fatores-chave das empresas clientes e das empresas fornecedoras eram significativamente diferentes. A seguir são mostrados os resultados, na Tabela 4.

Portanto, a partir dos testes mostrados na Tabela 4, ficaram evidente dois pontos. Primeiro, os fatores confiabilidade e qualidade estariam sincronizados. Os testes realizados não indicaram se as amostras seriam

Tabela 3 - Freqüência de repostas: cliente $\mathrm{x}$ fornecedores.

\begin{tabular}{|c|l|c|c|c|c|c|c|}
\hline \multirow{2}{*}{} & \multirow{2}{*}{ ESCALA } & \multicolumn{2}{c|}{ CONFIABILIDADE } & \multicolumn{2}{|c|}{ PREÇO } & \multicolumn{2}{c|}{ QUALIDADE } \\
\cline { 3 - 8 } & CLIENTE & FORNECEDOR & CLIENTE & FORNECEDOR & CLIENTE & FORNECEDOR \\
\hline (DT) & Discordo Totalmente & 0 & 0 & 2 & 8 & 0 & 0 \\
\hline (DM) & Discordo Muito & 1 & 0 & 0 & 5 & 0 & 0 \\
\hline (DP) & Discordo Pouco & 0 & 1 & 0 & 3 & 1 & 0 \\
\hline (CP) & Concordo Pouco & 0 & 2 & 6 & 12 & 1 & 0 \\
\hline (CM) & Concordo Muito & 11 & 13 & 13 & 16 & 5 & 6 \\
\hline (CT) & Concordo Totalmente & 26 & 35 & 17 & 7 & 31 & 45 \\
\hline Base de Dados (Válidos) & $\mathbf{3 8}$ & $\mathbf{5 1}$ & $\mathbf{3 8}$ & $\mathbf{5 1}$ & $\mathbf{3 8}$ & $\mathbf{5 1}$ \\
\hline
\end{tabular}

Tabela 4 - Teste não paramétrico.

\begin{tabular}{l|c|c|c|c|}
\multirow{2}{*}{ FATORES-CHAVE } & \multicolumn{3}{|c|}{ QUI-QUADRADO $\left(\chi^{2}\right)$} & MANN-WHITNEY \\
\cline { 2 - 5 } & $\chi^{2}$ CALCULADO & GRAUS DE LIBERDADE & NÍVEL DE SIGNIFICÂNCIA $(\alpha)$ & NIVEL DE SIGNIFICÂNCIA $(\alpha)$ \\
\hline Confiabilidade & 3,674 & 4 & 0,452 & 0,947 \\
\hline Preço & 16,531 & 5 & $0,005^{* *}$ & $0,000^{* *}$ \\
\hline Qualidade & 2,831 & 3 & 0,418 & 0,340
\end{tabular}

$\left({ }^{* *}\right)$ Significante no nível de $1 \%$ 
de populações diferentes, pelo menos no nível de significância (risco) de 5\%. Esse resultado pode ser devido ao fato de a aquisição de máquinas e equipamentos envolver contratos com cláusulas rigorosas para se evitarem falhas ou ineficiências de qualidade, sob pena de pagamento de multas ou indenizações onerosas. Quanto à confiabilidade da entrega, é um fator igualmente relevante, mas de menor implicação, porque uma falha no cumprimento do prazo, por exemplo, pode ser contornada ou negociada entre as partes.

Segundo ponto, o fator preço é discrepante, verificado da seguinte forma: a) o teste do Qui-Quadrado $\left(\chi^{2}\right)$ aponta uma baixa probabilidade para a hipótese $(p=0,005)$ de que elas sejam iguais. Em outras palavras, pode-se concluir que não existe evidência de associação ou dependência entre as duas partes; b) o teste de Mann-W hitney, significante no nível de $1 \%$ ( $\alpha=$ $0,000)$, evidencia que as amostras são diferentes, corroborando o resultado do teste do $\chi^{2}$. Retornando à Tabela 1, ficou evidente que existe 0 desejo de preço menor que 0 dos concorrentes $(68,6 \%$ das respostas no lado concordante da escala), mas não a sua real prática (56,8\% das respostas no lado discordante da escala). Por outro lado, o fator-chave preço apresentou uma boa consistência interna com seus atributos, como se pode verificar pelo Alfa de Cronbach igual a 0,7553 . Em termos práticos, isso pode ser interpretado da seguinte maneira: os insumos, em especial os materiais, têm uma participação importante nos custos das máquinas e equipamentos. Segundo dados da A bimaq, os materiais têm uma participação de 17,46\% nos custos dos produtos. Assim, qualquer aumento nos preços praticados pelos fornecedores, como por exemplo os materiais siderúrgicos, produz um impacto nos preços das máquinas. Além disso, a grande maioria dos fabricantes se abastece por meio de distribuidores e não dos grandes fornecedores, dada a pequena escala das suas demandas individuais. N esse caso, o ônus é muito maior. Outro fato importante é que a maioria dos pedidos de máquinas é para entrega a longo prazo, deixando o fabricante sob o risco do aumento de preços dos insumos no decorrer da produção da encomenda.

\section{Limitações do estudo}

$\mathrm{N}$ a definição do tamanho da amostra, em se tratando de uma amostra não probabilística, houve a preocupação em dimensioná-la com base nas experiências citadas em Hair et al. (1998) e Malhotra (1999). En- tretanto, o tamanho ficou limitado em função dos recursos e da disponibilidade de pessoal qualificado para a coleta. Além disso, cabe salientar que, ao se utilizar amostra não probabilística, as inferências extraídas da amostra devem ser ressalvadas, em função das limitações desse tipo de abordagem (Kerlinger, 1980). De qualquer maneira, este estudo procurou atender aos padrões científicos mínimos para permitir a sua posterior replicação, de maneira a corroborar ou refutar as evidências dele advindas (Popper, 1977).

\section{CONSIDERAÇÕES FINAIS}

0 ponto central do artigo foi verificar se as expectativas dos clientes estavam sincronizadas com as práticas gerenciais da cadeia de suprimentos de seus fornecedores, dentro de uma amostra não probabilística de empresas ligadas à Abimaq. Evidenciou-se o sincronismo para os fatores qualidade e confiabilidade, entre as empresas clientes e fornecedoras. Esse fato foi constatado pelas freqüências de respostas, testes $\chi^{2}$ e Mann-W hitney. A consistência interna dos atributos, dada pelo coeficiente Alfa de Cronbach para os fatores qualidade e confiabilidade, com val ores iguais a 0,6852 e 0,7930 respectivamente, mostraram-se consistentes.

O fator preço mostrou-se discrepante, ou seja, não foi evidenciado o sincronismo que na concepção da TOC (Theory of Constraints) constituiu o gargalo para a integração entre clientes e fornecedores. Esse resultado foi constatado pel os testes $\chi^{2}$ e $M$ ann-W hitney, que mostraram diferenças de respostas entre as duas partes. A consistência interna do fator preço, dada pelo coeficiente Alfa de Cronbach de 0,7553 , evidenciou que as práticas internas de gestão identificadas nos atributos tendem a seguir esse fator numa mesma direção. Além disso, a qualidade foi evidenciada como o fator de desempenho competitivo mais importante, tanto para os clientes como para os fornecedores.

Por fim, em função das características do setor estudado - ser estratégico e base para outras empresas produtoras - e dos resultados obtidos, é possível concluir que: a) o sincronismo dos fatores qualidade e confiabilidade refletiram a formalização das relações comerciais entre as empresas, isto é, baseadas em contratos; b) o fator preço constituiu o gargalo, devido aos custos dos materiais e riscos envolvidos (como 0 


\section{ARTIGOS •SINCRONISMO ENTRE CLIENTES E FORNECEDORES}

possível não cumprimento dos contratos formalizados) ; e c) a qualidade como principal fator de desempenho demonstrou que os executivos da Abimaq privilegiam o produto em suas demandas. Segundo Slack (1993) é fundamental ampliar esse enfoque, isto é, garantir um mínimo de qualidade aceitável, mas incluir no seu processo de negócios outros fatores-chave, como a confiabilidade, a velocidade e a flexibilidade, de forma síncrona, pelo seu efeito na cadeia de suprimentos.

Para futuras pesquisas, são dadas as seguintes sugestões. Primeiro, verificar se as empresas que ajustam o processo logístico para a qualidade dos produtos têm maior capacidade de obter vantagens competitivas do que aquelas que priorizam custos ou confiabilidade. Segundo, verificar o quanto as expectativas dos clientes se aproximam das práticas de gerenciamento logístico em outras cadeias de suprimentos, como autopeças e el etrodomésticos. E terceiro, ampliar a amostra e desenvolver estudos comparativos entre os diversos setores da economia, as diferentes origens do capital (nacional e estrangeiro), em bens de capital seriado e sob encomenda, ou mesmo diferentes regiões geográficas, para identificar os fatores-chave de desempenho competitivo e sua sincronia nos processos produtivos.

\section{REFERÊNCIAS BIBLIOGRÁFICAS}

ABIMAQ - Associação Brasileira da Indústria de Máquinas e Equipamentos. Disponível em <http://www.abimaq.com.br>. Acesso em 12 de out. 2004.

AROZO, R. CPFR - Planejamento colaborativo: em busca da redução de custos e aumento do nível de serviço nas cadeias de suprimentos. In: FLEURY, P. F.; FIGUEIREDO, K. F.; WANKE, P. Logística e gerenciamento da cadeia de suprimentos. Planejamento do fluxo de produtos e dos recursos. São Paulo: Atlas, 2003.

CHRISTOPHER, M. Logística e gerenciamento da cadeia de suprimentos. São Paulo: Pioneira, 1997.

CHRISTOPHER, M. A logística do marketing: otimizando processos para aproximar fornecedores e clientes. São Paulo: Futura, 1999.

COMEX. Diretrizes de política industrial, tecnologia e de comércio exterior. 2003.
COSTA NETO, P. L. O. Estatística. São Paulo: Edgard Blücher, 1977.

DAVIS, M. M.; AQUILAN O, N. J.; CHASE, R. B. Fundamentos da administração da produção. Porto Alegre: Bookman, 2001.

DORNIER, P.-P.; ERNST, R.; FENDER, M.; KOUVELIS, P. Logística e operações globais, textos e casos. São Paulo: Atlas, 2000.

FINE, C. H. M ercados em evolução contínua: conquistando vantagem competitiva num mundo em constante mutação. Rio de Janeiro: Campus, 1999.

GATTORNA, J. L.; WALTERS, D. W. Managing the Supply Chain: A Strategic Perspective. London: Macmillan Press, Ltd. 1996.

HAIR, J. F. et al. Multivariate Data Analysis. $5^{\text {th }}$ ed. Englewood Cliffs, NJ: Prentice Hall, 1998.

HAN DFIELD, R. B.; NICHOLS JR., E. L. Introduction to Supply Chain Management. Englewood Cliffs, NJ: Prentice Hall, 1999.

KANTER, R. M. Collaborative advantage: the art of alliances. H arvard Business Review, jul.-aug. 1994.

KAPLAN, R. S.; NORTON, D. P. Balanced scorecard: translating strategy into action. Harvard Business Review, p. 71-79, 1996.

KERLINGER, F. N. A metodologia da pesquisa em ciências sociais: um tratamento conceitual. São Paulo: EPU, 1980

KOTLER, P. M arketing para o século XXI: como criar, conquistar e dominar mercados. São Paulo: Futura, 1999.

MALHOTRA, N. K. Pesquisa de marketing: uma orientação aplicada. Porto Alegre: Bookman, 2001.

PEREIRA, J. C. R. A nálise de dados qualitativos: estratégias metodológicas para as ciências da saúde, humanas e sociais. São Paulo: Edusp/ Fapesp, 1999.

PIRES, S. L. I. Gestão da cadeia de suprimentos. São Paulo: Atlas, 2004.

POPPER, K. R. A lógica da pesquisa social. São Paulo: Cultrix, 1977.

PORTER, M. E. Vantagem competitiva. Rio de Janeiro: Campus, 1989.

RUSSELL, R. S.; TAYLOR III, B. W. Operations M anagement: Focusing on Quality and Competitiveness. Englewood Cliffs, NJ: Prentice Hall, 1998. 
SAATY, T. L. M étodo de análise hierárquica. São Paulo: McGraw-Hill, 1991.

SCHONBERGER, R. J.; KNOD JR., E. M. Serviço sincronizado. São Paulo: Pioneira, 1997.

SCHROEDER, R. G. Operations Management, Decision Making in the Operations Function. $4^{\text {th }}$ ed. New York: McGraw-Hill, 1993. p. 757993.
SLACK, N. Vantagem competitiva em manufatura. São Paulo: Atlas, 1993.

SLACK, N.; CHAMBERS, S.; JOH NSTON, R. Administração da produção. São Paulo: Atlas, 2002.

TUBIN O, D. F. Sistemas de produção: a produtividade no chão de fábrica. Porto Alegre: Bookman, 1999.

\title{
Artigo recebido em 26.05.2004. Aprovado em 17.05.2005.
}

\author{
Manuel Fernandes Silva Souza \\ Professor da Universidade Municipal de São Caetano do Sul. Mestre em Administração de \\ Empresas pelo Programa de Pós-Graduação em Administração da Universidade Presbiteriana \\ Mackenzie. \\ Interesses de pesquisa nas áreas de operações, logística e gestão da cadeia de suprimentos. \\ E-mail: fernandes@sptf.com.br \\ Endereço: Rua Antonio de Souza Delmundo, 245, Bairro Jardim Vila Formosa, São Paulo - \\ SP, 03470-160.
}

\section{Roberto Giro Moori}

Professor da Universidade Presbiteriana Mackenzie. Doutor em Engenharia de Produção pela Escola Politécnica da USP.

Interesses de pesquisa nas áreas de operações, logística e gestão da cadeia de suprimentos. E-mail: rgmoori@mackenzie.com.br

Endereço: Rua da Consolação, 896, 70 andar, sala 76, Bairro Consolação, São Paulo SP, 01302-907.

\section{Reynaldo Cavalheiro Marcondes}

Professor da Universidade Presbiteriana M ackenzie. Doutor em Administração de Empresas pela FEA-USP.

Interesses de pesquisa nas áreas de estratégias empresariais e desenvolvimento organizacional.

E-mail: reynaldo.marcondes@terra.com.br

Endereço: Rua da Consolação, 896, 7ํandar, sala 76, Bairro Consolação, São Paulo SP, 01302-907. 